\title{
Aldol Condensation-Type Group Transfer Copolymerizations of Silyl (Di)Enolates
}

\author{
Hiroshi Sumi, Kenji IshiKawa, Yoshihito InaI, \\ Tadamichi HirabaYASHI, and Kenji YoKOTA \\ Department of Materials Science and Engineering, Nagoya Institute of Technology, \\ Gokiso-cho, Showa-ku, Nagoya 466, Japan
}

(Received June 7, 1994)

\begin{abstract}
Copolymerizations of two monomers among silyl dienolates, $\mathrm{CH}_{2}=\mathrm{CR}^{1}-\mathrm{CH}=$ $\mathrm{CH}-\mathrm{OSi}\left(\mathrm{CH}_{3}\right)_{2} \mathrm{R}^{2}$ and silyl enolates $\mathrm{CH}_{2}=\mathrm{CH}-\mathrm{OSi}\left(\mathrm{CH}_{3}\right)_{2} \mathrm{R}^{2}\left[\mathrm{R}^{1}=\mathrm{H}, \mathrm{CH}_{3} ; \mathrm{R}^{2}=\mathrm{CH}_{3}, \mathrm{C}\left(\mathrm{CH}_{3}\right)_{3}\right]$ were examined under conditions suitable for aldol condensation-type group transfer polymerization (aldol-GTP). Structures of the copolymers were determined mainly by their ${ }^{1} \mathrm{H}$ NMR spectra and by partial desilylation. $E$-isomers of dienolates $\left(\mathrm{R}^{1}=\mathrm{H}\right)$ showed much higher copolymerizability than enolates, independent of $\mathrm{R}^{2}$ substituent on silicon. Methyl substituent at 3-carbon $\left(\mathrm{R}^{1}=\mathrm{CH}_{3}\right)$ enhanced the copolymerizability of silyl dienolate further. $Z$-dienolates could hardly react with $E$-isomers but gave rise to copolymerization with the enolate monomer. 1:1 Aldol-adducts of the above monomers with benzaldehyde were prepared. The adducts were effective initiators for aldol-GTP of other monomers. The results provided evidence for the existence of cross-propagation on aldol group transfer copolymerization.

KEY WORDS Group Transfer Polymerization / Copolymerization / 1-Butadienyloxytrimethylsilane / Vinyloxytrimethylsilane / Monomer Reactivity Ratio / Desilylation /
\end{abstract}

Since aldol condensation-type group transfer polymerization (aldol-GTP) of $t$-butyldimethylvinyloxysilane (VOTBDMS) was reported ${ }^{1}$ by Du Pont, it has been found an excellent method for the preparation of a poly(vinyl alcohol) unit with controlled molecular weight. Block copolymers ${ }^{1,2}$ and macromonomers ${ }^{3}$ containing such units were prepared successfully.

Aldol-GTPs of 1-butadienyloxytrimethylsilane (BdTMS) and its derivatives substituted with methyl (MeBdTMS) or phenyl (PhBdTMS) groups at 3-position have been investigated. ${ }^{4-10}$ It was found that (1) $p$ anisaldehyde as an initiator ${ }^{5}$ and zinc bromide $\left(\mathrm{ZnBr}_{2}\right)$ as a catalyst ${ }^{6}$ were most effective for the control of the molecular weights of polymers, (2) a polymerization mixture could be made homogeneous by using $\mathrm{ZnBr}_{2}$ solution in a small amount of diethyl ether in toluene even at $-78^{\circ} \mathrm{C}$, where undesirable side reactions were almost extinguished, ${ }^{7}$ (3) $E$-isomers of silyl dienolates could readily polymerize, while $Z$-isomers not at all under the same conditions ${ }^{9}$ and (4) the configuration around a double bond in silyl dienolate polymers was reflected by the conformation of monomers at the ground state. ${ }^{10}$ Based on stereochemical and kinetic data, ${ }^{8-10}$ we proposed a bicyclic transition state model for propagation of aldol-GTP.

Systematical studies on copolymerization of two monomers among silyl dienolates and/or silyl enolates have not been examined yet. A comparison of reactivity ratios between the monomers under conditions suitable for aldol-GTP must lead to some useful discussions, which is in no way inferior to that based on stereochemical and kinetic data. In this paper, we deal with statistical copolymeriza- 
tions of several pairs of monomers among the following silyl enolates and dienolates and discuss the mechanism of aldol-GTP.

$$
\begin{aligned}
\mathrm{CH}_{2}= & \mathrm{C} \mathrm{H} \\
& \text { OSiMe2R }
\end{aligned}
$$

VOTMS : R, Me

VOTBDMS: $R,{ }^{t_{B u}}$

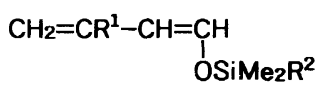

BdTMS : $\mathrm{R}^{1}, \mathrm{H} ; \mathrm{R}^{2}, \mathrm{Me}$

MeBdTMS: $R^{1}, M e ; R^{2}, M e$

BdTBDMS: $\mathrm{R}^{\mathbf{1}}, \mathrm{H} ; \mathrm{R}^{\mathbf{2}} \mathrm{t}_{\mathrm{Bu}}$

\section{EXPERIMENTAL}

\section{Monomer Syntheses}

VOTMS and VOTBDMS. According to the literature, ${ }^{11}$ vinyloxylithium was prepared from THF and $n$-butyllithium at first, then VOTMS and VOTBDMS were synthesized by addition of the corresponding silyl chlorides, $\mathrm{R}\left(\mathrm{CH}_{3}\right)_{2} \mathrm{SiCl}$. VOTMS: bp $58^{\circ} \mathrm{C} / 65 \mathrm{mmHg}$; yield, $74 \%$. VOTBDMS: bp $75^{\circ} \mathrm{C}$; yield, $90 \%$.

$E-B d T M S$ and E-MeBdTMS. These monomers were prepared in the same manner as described in the previous papers. ${ }^{6,9} E$-BdTMS: bp $62^{\circ} \mathrm{C} / 65 \mathrm{mmHg}$; yield, $65 \%$. $E$-MeBdTMS: bp $73^{\circ} \mathrm{C} / 75 \mathrm{mmHg}$; yield, $74 \%$.

$E-B d T B D M S$. Under a nitrogen atmosphere, pure $E$-BdTMS $(31.2 \mathrm{~g}, 0.22 \mathrm{~mol})$ in $300 \mathrm{ml}$ of tetrahydrofuran (THF) was mixed with $n$-butyllithium $\left(10 \mathrm{moll}^{-1}\right.$ in $n$-hexane, $25 \mathrm{ml}$ ) at $-78^{\circ} \mathrm{C}$. The mixture was stirred for $1 \mathrm{~h}$ at $-78^{\circ} \mathrm{C}$, warmed to ambient temperature, and stirred for $2 \mathrm{~h}$. A solution of $t$ butyldimethylchlorosilane $(32.2 \mathrm{~g}, 0.21 \mathrm{~mol})$ in $100 \mathrm{ml}$ of THF was added dropwise to the mixture. The reaction mixture was stirred for $2 \mathrm{~h}$ at ambient temperature. The solvent was evaporated, and the crude product was distilled under reduced pressure to give $35.4 \mathrm{~g}$ of BdTBDMS: bp $52^{\circ} \mathrm{C} / 5 \mathrm{mmHg}$; yield, $90 \%$.

Z-BdTMS and Z-BdTBDMS. The monomers were prepared from 2-phenyl-1,3-dioxacyclohept-5-ene according to the method in the literature. ${ }^{12} \mathrm{Z}$-BdTMS: bp $64^{\circ} \mathrm{C} / 75 \mathrm{mmHg}$; yield, $73 \%$. Z-BdTBDMS: bp $42^{\circ} \mathrm{C} / 3 \mathrm{mmHg}$; yield, $37 \%$.

\section{1:1 Aldol-Adducts}

1:1 Aldol-adducts of benzaldehyde and monomers, BdTMS, MeBdTMS, BdTBDMS, and VOTBDMS, were prepared in the same manner as in the previous paper. ${ }^{9}$

\section{Other Materials}

Benzaldehyde and $p$-anisaldehyde were fractionally distilled under reduced pressure before use. $\mathrm{ZnBr}_{2}$ was sublimed in vacuo and used as a $1.6 \mathrm{moll}^{-1}$ solution in diethyl ether distilled over sodium. Toluene and benzene were purified by the conventional method, dried over sodium in the presence of benzophenone, and distilled before use.

\section{Copolymerization}

A flask equipped with a stopcock was flame-dried in vacuo for about $2 \mathrm{~min}$ and then allowed to cool under nitrogen. The flask was charged with calculated amounts of $p$ anisaldehyde, toluene, and two monomers under nitrogen atmosphere, and capped with a septum. The mixture was cooled to $0^{\circ} \mathrm{C}$ and stirred for about $15 \mathrm{~min}$. A calculated amount of $\mathrm{ZnBr}_{2}$ solution in diethyl ether and toluene was rapidly added to the stirred mixture via a syringe through the septum cap. After an adequate period, a small amount of mixture of methanol and triethylamine $(1: 1 \mathrm{v} / \mathrm{v})$ was added to the reaction mixture. The reaction mixture was washed once with $5 \%$ aqueous sodium hydrogen carbonate solution and three times with water. The organic layer was dried over magnesium sulfate, filtered, and concentrated in vacuo to give a product copolymer. The copolymer was further dried in vacuo for more than 3 days at ambient temperature. Conversion of monomers was determined by gravimetry of the product copolymer. A copolymer including BdTBDMS as a comonomer was lyophilized more than three times to remove unchanged BdTBDMS.

\section{Polymer Reactions}

Desilylation. Desilylation of polymer with 
trimethylsilyl and $t$-butyldimethylsilyl groups was done using THF-acetic acid-water $(5: 3$ : 1). A mixture of acetic acid and water was added dropwise into the polymer solution in $\mathrm{THF}$ with vigorous stirring. The mixture was stirred at ambient temperature for $20 \mathrm{~h}$, and concentrated by evaporation. The product was reprecipitated three times from methanol solution with diethyl ether, and dried in vacuo to give a white powder. Only trimethylsilyl groups were desilylated, and $t$-butyldimethylsilyl groups remained.

Acetylation. The desilylated copolymer was dissolved in pyridine. Acetic anhydride was added dropwise to the solution at ambient temperature. The mixture was homogeneous throughout the reaction, but turned brown. After $74 \mathrm{~h}$, the mixture was concentrated by evaporation. The crude product was dissolved in benzene and lyophilized three times. A brown powder was obtained.

\section{Analyses}

${ }^{1} \mathrm{H}$ and ${ }^{13} \mathrm{C}$ NMR spectra were recorded with a Varian XL-200 spectrometer in deuterochloroform. Molecular weight and molecular weight distribution were determined by gel permiation chromatography (GPC) in THF eluent using a Tosoh HLC-803D equipped with a differential refractive index detector and four
TSK gel columns, G5000-, G4000-, G3000-, G2000-HXL, connected in series. Molecular weights were calibrated with standard polystyrenes.

\section{RESULTS AND DISCUSSION}

Aldol-GTP using 1:1 Aldol Adducts as an Initiator

In aldol-GTP of silyl dienolates or enolates, initiation and propagation are recognized as nucleophilic addition of the monomers to formyl group on an initiator and a polymer end, respectively. If two monomers give rise to copolymerization by way of aldol-GTP, the following conditions must be satisfied: (1) each monomer can react with the initiator to yield an 1:1 aldol-adduct; (2) the adduct has a formyl group and should work as the initiator for aldol-GTP of the comonomer.

In preference to copolymerization experiments, $1: 1$ aldol-adducts of benzaldehyde with BdTMS, MeBdTMS, BdTBDMS, and VOTBDMS were prepared as shown in Scheme 1 , and used as the initiators for aldol-GTP of the above monomers. Only when benzaldehyde was used at five-fold concentration of monomer, 1:1 aldol-adducts could be isolated. Otherwise further addition of the monomer occurred to give an oligomer. The structures

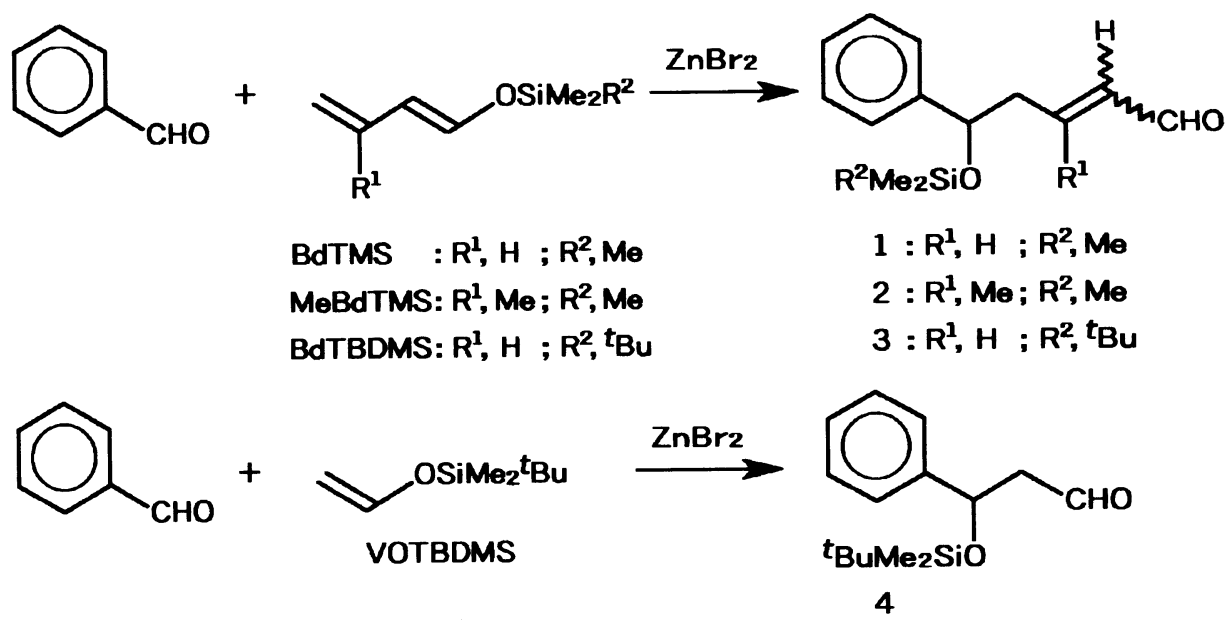

Scheme 1. 
of $1: 1$ aldol-adducts, $1-4$, were confirmed by ${ }^{1} \mathrm{H}$ and ${ }^{13} \mathrm{C}$ NMR and IR spectra. The results are summarized in Table I.

Aldol-GTP of the monomers, BdTMS, MeBdTMS, BdTBDMS, and VOTBDMS were carried out in the presence of $1: 1$ aldoladducts, $1-4$, as initiators. The results are summarized in Table II. It has already been noted that 1 could react with BdTMS itself to yield the homopolymer of BdTMS. Now it is clearly found that every $1: 1$ aldol-adduct can

Table I. 1:1 Aldol-adducts of benzaldehyde with silyl dienolates $^{\mathrm{a}}$ and VOTBDMS

\begin{tabular}{|c|c|c|c|c|c|}
\hline \multirow{3}{*}{ Run } & \multirow{3}{*}{ Monomer } & \multicolumn{4}{|c|}{$1: 1$ Aldol-adduct } \\
\hline & & \multirow{2}{*}{ Code } & Yield $^{\mathrm{b}}$ & $\mathrm{bp}$ & Configuration \\
\hline & & & $\%$ & ${ }^{\circ} \mathrm{C} / \mathrm{mmHg}$ & $E: Z$ \\
\hline 1 & BdTMS & 1 & 48 & $103 / 0.4$ & 100: 0 \\
\hline 2 & MeBdTMS & 2 & 18 & $106 / 0.2$ & $77: 23$ \\
\hline 3 & BdTBDMS & 3 & 64 & $140 / 0.2$ & 100: 0 \\
\hline 4 & VOTBDMS & 4 & 67 & $104 / 0.6$ & - \\
\hline
\end{tabular}

a $E$-Isomers were used.

b Isolated yield. give rise to the aldol-GTP of not only monomers included in the adducts but also other monomers. This suggests that cross propagation units, e.g., MeBdTMS $\rightarrow$ BdTMS and BdTMS $\rightarrow$ MeBdTMS, exist if group transfer copolymerizations (aldol-coGTP) of these monomers are carried out.

Figure 1 shows ${ }^{1} \mathrm{H}$ NMR spectra of 3 and the VOTBDMS oligomer initiated with 3 (run 9 in Table II). Peaks due to olefinic protons in 3 appeared at $6.0-6.9 \mathrm{ppm}$, and the peaks disappeared completely in the oligomer spectrum. A new olefinic peak due to 3 residue appeared at $5.2-5.4 \mathrm{ppm}$. A singlet peak at $9.7 \mathrm{ppm}$ was assigned to formyl proton of the propagating oligomer end. Formyl proton of 3 was characterized by doublet at $9.5 \mathrm{ppm}$. These changes indicate that the aldol-GTP of VOTBDMS was initiated with $\mathbf{3}$, as shown in Scheme 2.

Molecular weights of the oligomers (runs $1-9$ in Table II) agreed with those calculated based on the living behavior of the polymerization. However, the control of molecular weight was not good in the case of $\mathbf{4}$ as an initiator

Table II. Aldol-GTP by use of 1:1 aldol-adduct as an initiator ${ }^{\mathrm{a}}$

\begin{tabular}{|c|c|c|c|c|c|c|c|c|}
\hline \multirow{2}{*}{ Run } & \multirow{2}{*}{ Initiator } & \multirow{2}{*}{ Monomer $^{b}$} & \multirow{2}{*}{$\frac{\text { Time }}{\mathrm{h}}$} & \multirow{2}{*}{$\begin{array}{c}\text { Yield } \\
\%\end{array}$} & \multicolumn{3}{|c|}{$M_{n}$} & \multirow{2}{*}{$\frac{M_{w}{ }^{\mathrm{c}}}{M_{n}}$} \\
\hline & & & & & $\mathrm{GPC}^{\mathrm{c}}$ & $\mathrm{NMR}^{\mathrm{d}}$ & Calcd $^{\mathrm{e}}$ & \\
\hline 1 & 1 & MeBdTMS & 2.0 & 66 & 770 & 990 & 870 & 1.27 \\
\hline 2 & 1 & BdTBDMS & 3.0 & 66 & 1300 & 1300 & 1250 & 1.34 \\
\hline 3 & 1 & VOTBDMS & 2.0 & 91 & 890 & 840 & 880 & 1.22 \\
\hline 4 & 2 & BdTMS & 3.5 & 87 & 1220 & 1500 & 1280 & 1.25 \\
\hline 5 & 2 & BdTBDMS & 2.5 & 76 & 910 & 1270 & 1050 & 1.27 \\
\hline 6 & 2 & VOTBDMS & 2.0 & 68 & 910 & 980 & 1030 & 1.16 \\
\hline 7 & 3 & BdTMS & 2.0 & 84 & 1060 & 950 & 1000 & 1.21 \\
\hline 8 & 3 & MeBdTMS & 1.8 & 52 & 720 & 790 & 780 & 1.19 \\
\hline 9 & 3 & VOTBDMS & 1.0 & 59 & 910 & 850 & 850 & 1.16 \\
\hline 10 & 4 & BdTMS & 2.5 & 74 & 2100 & 1690 & 890 & 1.85 \\
\hline 11 & 4 & MeBdTMS & 2.5 & 62 & 1500 & 1460 & 840 & 2.25 \\
\hline 12 & 4 & BdTBDMS & 2.5 & 77 & 2400 & 2690 & 1110 & 3.60 \\
\hline
\end{tabular}

a Carried out in the presence of $\mathrm{ZnBr}_{2}\left(1.6 \mathrm{moll}^{-1}\right.$ solution in diethyl ether) in toluene at $0^{\circ} \mathrm{C}$ : $[\mathrm{Monomer}]_{0}$, $1.0 \mathrm{moll}^{-1}$; [Initiator $]_{0}, 167 \mathrm{mmoll}^{-1} ;\left[\mathrm{ZnBr}_{2}\right]_{0}, 56 \mathrm{mmoll}^{-1}$.

b $E$-Isomers of BdTMS, MeBdTMS, and BdTBDMS were used.

c Determined by GPC and calibrated by standard polystyrenes.

d Determined by end group analysis.

e Calculated from (mol wt of initiator $)+($ mol wt of monomer $) \times 6 \times$ Yield/100. 

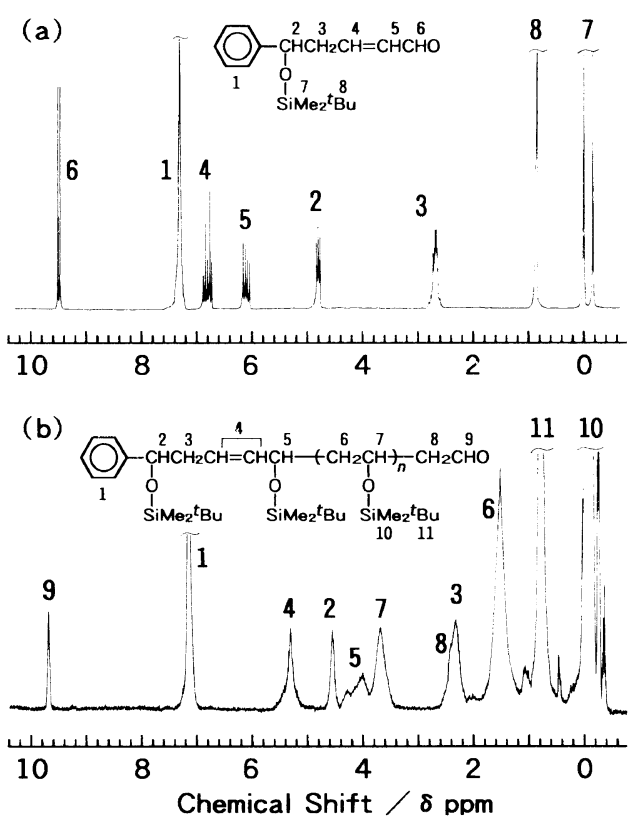

Figure 1. ${ }^{1} \mathrm{H}$ NMR spectra of (a) 3 and (b) oligomer of VOTBDMS initiated with 3 .
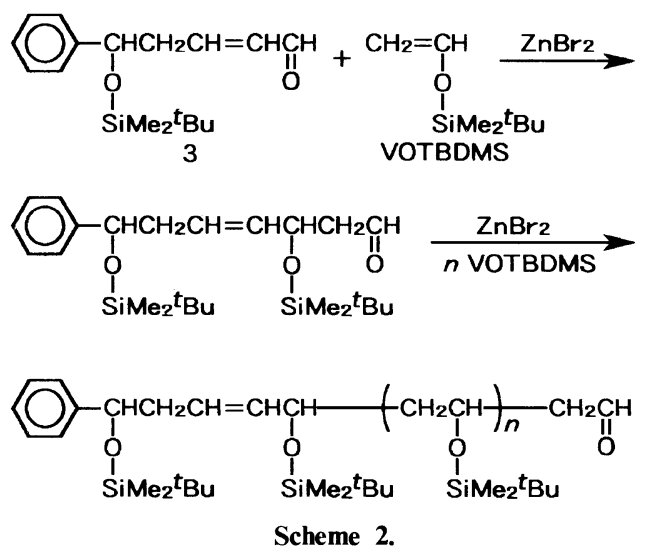

(runs 10-12) compared with three other initiators, 1-3. Unchanged 4 was detected in the ${ }^{1} \mathrm{H}$ NMR spectrum and GPC profile of the reaction mixture in runs $10-12$. Although 4 showed incomplete initiating ability for the aldol-GTP of silyl dienolates, the resulting adducts of 4 with the dienolate monomers must be conjugated aldehydes which can be followed by rapid propagation. Similar results were obtained in our previous study on the initiating ability of various aldehydes. ${ }^{5}$ No polymerization commenced by 4 at $-78^{\circ} \mathrm{C}$, while aldol-GTP with $\mathbf{1}-\mathbf{3}$ proceeded after a somewhat long time even at $-78^{\circ} \mathrm{C}$. These initiations with $\mathbf{1 - 4}$ are just models for cross propagations in aldol-coGTP. Therefore, poor copolymerizability of VOTBDMS can be predicted on aldol-coGTP with dienolate comonomers, BdTMS, MeBdTMS, and BdTBDMS.

\section{Conditions of Aldol-CoGTP}

To get significant data from aldol-coGTP, it is necessary to set experimental conditions carefully. Since the aldol-GTP proceeds in a living manner, the degree of polymerization is in proportion to conversion of feed monomer. The degree of polymerization must be high ( $\geqq 30$ ) enough to treat copolymer composition statistically. Thus, the theoretical degree of polymerization at $100 \%$ conversion was set at 300 , and polymerization time was adjusted so as to become about $10 \%$ conversion by way of trial and error. The extended Kelen-Tüdös method $^{13}$ must be useful to determine reactivity ratios, $r_{1}$ and $r_{2}$, even if the monomer conversions were somewhat over $10 \%$. Polymerization temperature at $-78^{\circ} \mathrm{C}$ was preferred in the aldol-GTP of silyl dienolate monomers to avoid undesirable side reactions by which termination occurs. ${ }^{7}$ However, the aldol-GTP of silyl enolate monomers, VOTMS and VOTBDMS, did not proceed at $-78^{\circ} \mathrm{C}$. Thus aldol-coGTP was carried out at $0^{\circ} \mathrm{C}$. On the basis of our previous studies, ${ }^{5-7} p$ anisaldehyde and $\mathrm{ZnBr}_{2}$ solution in diethyl ether were selected as the initiator and Lewis acid catalyst, respectively. Benzaldehyde was also used as an initiator in some experiments.

Flame-drying of glass apparatus and sufficient drying of the reagents should be done thoroughly to avoid undesired hydrolysis of the monomer. Otherwise, some aldehyde will be produced from the monomer in the reaction mixture and the degree of polymerization may decrease to less the theoretical value. 
Effects of structure features of the monomers on their reactivity toward the aldol-GTP may be understood through copolymerization of the following comonomer pairs.

(1) Effects of organosilyl groups ( $t$-butyldimethylsilyl and trimethylsilyl groups): VOTBDMS-VOTMS, BdTBDMS-BdTMS.

(2) Differences between silyl enolate and silyl dienolate monomers: VOTBDMSBdTBDMS, VOTMS-BdTMS.

(3) Effects of 3-substituent of silyl dienolate monomers: BdTMS-MeBdTMS.

(4) Differences in geometry of silyl dienolate monomers: $E$-BdTBDMS-Z-BdTBDMS, $E$-BdTMS-Z-BdTMS.

In the experiments on (1)-(3), $E$-isomers were used as silyl dienolate monomers.
Effects of Organosilyl Groups in Aldol-CoGTP

At first, the effects of organosilyl groups, $t$-butyldimethylsilyl (TBDMS) and trimethylsilyl (TMS) groups, on the aldol-coGTP were investigated for VOTBDMS-VOTMS or BdTBDMS-BdTMS. The results are summarized in Table III. Figures 2 and 3 show the ${ }^{1} \mathrm{H}$ NMR spectra of the copolymers obtained in runs 11 and 3, respectively. Signals of poly(BdTBDMS) agreed in chemical shifts with those of poly(BdTMS) except for methyl signals due to TBDMS and TMS groups. Therefore, the signals of copolymer overlapped regardless of BdTBDMS or BdTMS units in Figure 2. The same situation holds also for Figure 3. Copolymer compositions were calculated from signal intensities of TBDMS and TMS groups. Figure 4 shows copolymer

Table III. Aldol-coGTP of VOTBDMS-VOTMS and BdTBDMS-BdTMS at $0^{\circ} \mathrm{C}^{\mathrm{a}}$

\begin{tabular}{|c|c|c|c|c|c|c|}
\hline \multirow{2}{*}{ Run } & \multirow{2}{*}{$\begin{array}{l}\text { Monomer feed } \\
\mathrm{mol}^{2} \text { of } \mathrm{M}_{1}\end{array}$} & \multirow{2}{*}{$\frac{\text { Time }}{\min }$} & \multirow{2}{*}{$\begin{array}{c}\text { Yield } \\
\%\end{array}$} & \multicolumn{3}{|c|}{ Copolymer } \\
\hline & & & & $\mathrm{mol} \%$ of $\mathrm{M}_{1}$ & $M_{n}^{\mathrm{b}} \times 10^{-3}$ & $M_{w} / M_{n}^{\mathrm{b}}$ \\
\hline \multicolumn{7}{|c|}{$\operatorname{VOTBDMS}\left(\mathrm{M}_{1}\right)-\operatorname{VOTMS}\left(\mathrm{M}_{2}\right)^{\mathrm{c}}$} \\
\hline 1 & 89.4 & 15 & 12.2 & 89 & 2.1 & 1.64 \\
\hline 2 & 74.6 & 12 & 10.5 & 74 & 2.0 & 1.60 \\
\hline 3 & 50.1 & 9 & 7.9 & 47 & 1.4 & 1.59 \\
\hline 4 & 24.9 & 15 & 9.3 & 22 & 1.7 & 1.61 \\
\hline 5 & 10.2 & 20 & 8.3 & 9 & 1.3 & 1.51 \\
\hline \multicolumn{7}{|c|}{$\operatorname{BdTBDMS}\left(\mathrm{M}_{1}\right)-\operatorname{BdTMS}\left(\mathbf{M}_{2}\right)^{\mathrm{c}}$} \\
\hline 6 & 90.3 & 5 & 15.1 & 93 & 5.5 & 1.69 \\
\hline 7 & 83.6 & 5 & 9.5 & 86 & 6.5 & 1.57 \\
\hline 8 & 74.9 & 3.5 & 34.0 & 76 & 15.2 & 1.76 \\
\hline 9 & 49.9 & 3 & 15.4 & 49 & 7.1 & 1.41 \\
\hline 10 & 24.7 & 3 & 13.2 & 18 & 3.4 & 2.14 \\
\hline 11 & 9.8 & 3 & 10.8 & 10 & 2.5 & 1.61 \\
\hline \multicolumn{7}{|c|}{$\operatorname{BdTBDMS}\left(\mathrm{M}_{1}\right)-\operatorname{BdTMS}\left(\mathrm{M}_{2}\right)^{\mathrm{d}}$} \\
\hline 12 & 83.3 & 1 & 3.0 & 86 & 1.0 & 1.45 \\
\hline 13 & 49.9 & 3 & 23.3 & 53 & 4.3 & 1.70 \\
\hline 14 & 24.7 & 3 & 26.0 & 19 & 3.8 & 1.89 \\
\hline 15 & 9.8 & 2.5 & 20.8 & 13 & 3.6 & 1.84 \\
\hline
\end{tabular}

a Carried out with $p$-anisaldehyde (runs $1-5$ and 12-15) or benzaldehyde (runs 6-11) as an initiator in the presence of $\mathrm{ZnBr}_{2}\left(1.6 \mathrm{moll}^{-1}\right.$ solution in diethyl ether): $\left(\left[\mathrm{M}_{1}\right]_{0}+\left[\mathrm{M}_{2}\right]_{0}\right), 1.0 \mathrm{moll}^{-1}$; $[p \text {-anisaldehyde }]_{0}$, $3.3 \mathrm{mmol}^{-1} ;\left[\mathrm{ZnBr}_{2}\right]_{0}, 3.3 \mathrm{mmol}^{-1}$.

b Determined by GPC and calibrated by standard polystyrenes.

c Carried out in toluene.

d Carried out in $\mathrm{CH}_{2} \mathrm{Cl}_{2}$. 
H. Sumi et al.

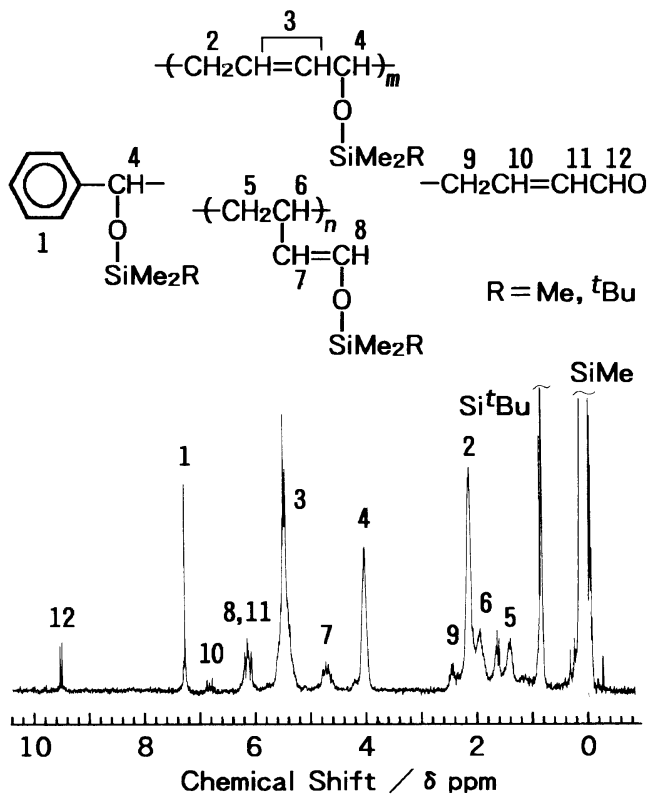

Figure 2. ${ }^{1} \mathrm{H}$ NMR spectrum of copolymer of BdTBDMS and BdTMS (run 11 in Table III).
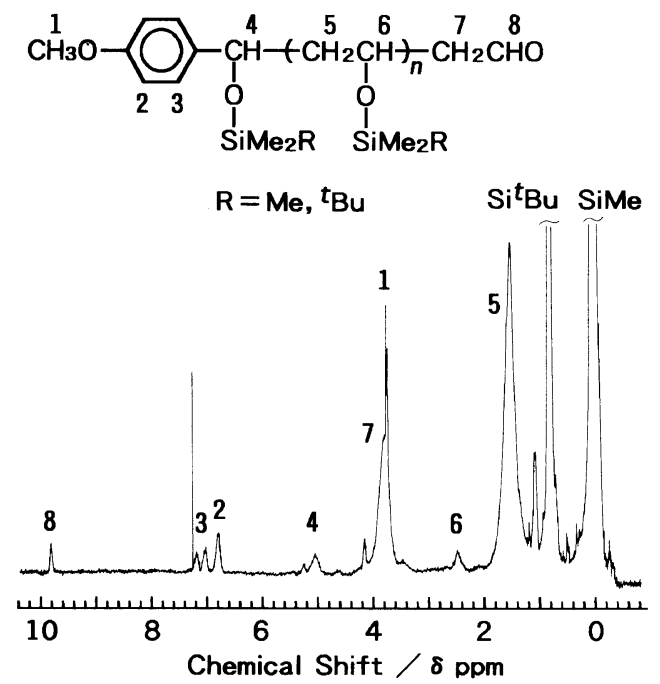

Figure 3. ${ }^{1} \mathrm{H}$ NMR spectrum of copolymer of VOTBDMS and VOTMS (run 3 Table III).

composition diagrams in aldol-coGTP of VOTBDMS-VOTMS (runs $1-5$ in Table III) and BdTBDMS-BdTMS (runs 6-11). Both curves apply to ideal copolymerization. The TMS or TBDMS group in the monomer does

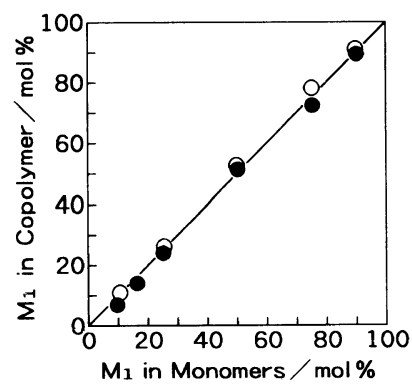

Figure 4. Copolymer composition diagrams in aldolcoGTP: O, VOTBDMS $\left(M_{1}\right)-\operatorname{VOTMS}\left(\mathrm{M}_{2}\right)$; $\operatorname{BdTBDMS}\left(\mathrm{M}_{1}\right)-\operatorname{BdTMS}\left(\mathrm{M}_{2}\right)$.

not bring about significant difference in copolymerizability.

In spite of a different organosilyl group, ${ }^{13} \mathrm{C}$ chemical shifts of BdTBDMS and BdTMS were almost the same, i.e., $\mathrm{C}_{1}, 145.8 ; \mathrm{C}_{2}, 114.6$; $\mathrm{C}_{3}, 133.8 ; \mathrm{C}_{4}, 112.3$ for BdTBDMS: $\mathrm{C}_{1}, 145.2$; $\mathrm{C}_{2}, 114.9 ; \mathrm{C}_{3}, 133.8 ; \mathrm{C}_{4}, 112.5 \mathrm{ppm}$ for BdTMS (chemical shifts are based on $77.5 \mathrm{ppm}$ of $\mathrm{CDCl}_{3}$ ). Thus there is little difference in the nucleophilicity of monomers at $\mathrm{C}_{4}$ toward the cationic propagating center. The structure of the propagating polymer end may be important to determine copolymerizability. However, the same propagating end was formed regardless of the incoming monomers as shown in Scheme 3. Therefore the above results should be explained only by the reactivity of incoming monomers. Among processes involved in aldol-GTP, transfer of an organosilyl group from the incoming monomer to the formyl oxygen of the propagating polymer end is absolutely required. If this process should be a rate-determining step in aldol-GTP, the reactivity of incoming monomers should be

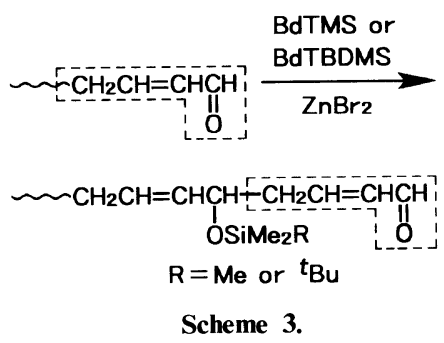

Polym. J., Vol. 27, No. 1, 1995 
influenced directly by the organosilyl group, probably by its different size. However, such an assumption is shown invalid by the above results. A possible reaction path will be discussed later.

Aldol-coGTP of BdTBDMS and BdTMS was carried out in $\mathrm{CH}_{2} \mathrm{Cl}_{2}$ instead of toluene (runs $12-15$ in Table III). The mole fraction of BdTBDMS in the copolymer was close to that of BdTBDMS in the feed. Ideal copolymerization was observed in $\mathrm{CH}_{2} \mathrm{Cl}_{2}$ as well as in toluene. Although aldol-GTP has been recognized as a kind of cationic polymerization, the solvent had little influence on aldol-coGTP. This assured us that the same active species was induced from both monomers in the same way. The use of $p$ anisaldehyde instead of benzaldehyde resulted in ideal copolymerization. This is reasonable in aldol-GTP because the initiator contributes only to the initiation and cannot be responsible for competitive propagations between the monomers.

\section{Differences between Silyl Enolate and Silyl} Dienolate Monomers

Aldol-coGTP of the silyl dienolate monomer (BdTBDMS or BdTMS) and silyl enolate monomer (VOTBDMS or VOTMS) were carried out. The results are summarized in

Table IV. Aldol-coGTP between silyl dienolate and silyl enolate in toluene at $0^{\circ} \mathrm{C}^{\mathrm{a}}$

\begin{tabular}{|c|c|c|c|c|c|c|}
\hline \multirow{2}{*}{ Run } & \multirow{2}{*}{$\begin{array}{c}\text { Monomer feed } \\
\mathrm{mol} \% \text { of } \mathrm{M}_{1}\end{array}$} & \multirow{2}{*}{$\frac{\text { Time }}{\min }$} & \multirow{2}{*}{$\begin{array}{c}\text { Yield } \\
\%\end{array}$} & \multicolumn{3}{|c|}{ Copolymer } \\
\hline & & & & $\mathrm{mol} \%$ of $\mathrm{M}_{1}$ & $M_{n}^{\mathrm{b}} \times 10^{-3}$ & $M_{w} / M_{n}^{\mathrm{b}}$ \\
\hline \multicolumn{7}{|c|}{$\operatorname{BdTBDMS}\left(\mathrm{M}_{1}\right)$-VOTBDMS($\left(\mathrm{M}_{2}\right)$} \\
\hline 1 & 74.9 & 2.5 & 8.8 & 97 & 3.0 & 2.00 \\
\hline 2 & 49.9 & 3 & 6.2 & 93 & 2.4 & 1.83 \\
\hline 3 & 35.0 & 3 & 11.4 & 85 & 4.1 & 1.87 \\
\hline 4 & 24.9 & 7 & 12.1 & 73 & 3.6 & 1.82 \\
\hline 5 & 9.9 & 7 & 10.4 & 34 & 3.5 & 2.06 \\
\hline \multicolumn{7}{|c|}{$\operatorname{BdTBDMS}\left(\mathrm{M}_{1}\right)-\operatorname{VOTMS}\left(\mathrm{M}_{2}\right)$} \\
\hline 6 & 74.5 & 3 & 14.6 & 95 & 4.8 & 2.00 \\
\hline 7 & 50.1 & 3 & 10.1 & 90 & 3.6 & 2.00 \\
\hline 8 & 35.1 & 5 & 12.8 & 79 & 3.1 & 1.86 \\
\hline 9 & 24.9 & 6.5 & 12.3 & 64 & 2.4 & 1.72 \\
\hline 10 & 10.0 & 19 & 13.7 & 22 & 2.7 & 1.63 \\
\hline \multicolumn{7}{|c|}{$\operatorname{BdTMS}\left(\mathrm{M}_{1}\right)-$ VOTBDMS$\left(\mathrm{M}_{2}\right)$} \\
\hline 11 & 75.0 & 2.5 & 8.8 & 96 & 1.4 & 1.72 \\
\hline 12 & 50.2 & 10 & 8.2 & 89 & 1.5 & 1.46 \\
\hline 13 & 35.0 & 10 & 17.1 & 77 & 2.7 & 1.79 \\
\hline 14 & 25.6 & 12 & 15.0 & 67 & 2.6 & 1.78 \\
\hline 15 & 10.2 & 12 & 13.8 & 31 & 1.9 & 1.73 \\
\hline \multicolumn{7}{|c|}{$\operatorname{BdTMS}\left(\mathrm{M}_{1}\right)-\operatorname{VOTMS}\left(\mathrm{M}_{2}\right)$} \\
\hline 16 & 74.6 & 1.5 & 13.6 & 95 & 3.9 & 1.8 \\
\hline 17 & 50.3 & 7 & 18.7 & 87 & 3.9 & 1.8 \\
\hline 18 & 34.6 & 7 & 13.3 & 71 & 3.5 & 1.7 \\
\hline 19 & 24.6 & 9 & 11.4 & 56 & 2.7 & 1.7 \\
\hline 20 & 10.3 & 10 & 8.5 & 26 & 2.1 & 1.5 \\
\hline
\end{tabular}

a Carried out with $p$-anisaldehyde as an initiator in the presence of $\mathrm{ZnBr}_{2}\left(1.6 \mathrm{~mol}^{-1}\right.$ solution in diethyl ether): $\left(\left[\mathrm{M}_{1}\right]_{0}+\left[\mathrm{M}_{2}\right]_{0}\right), 1.0 \mathrm{moll}^{-1} ;[p \text {-anisaldehyde }]_{0}, 3.3 \mathrm{mmoll}^{-1} ;\left[\mathrm{ZnBr}_{2}\right]_{0}, 3.3 \mathrm{mmoll}^{-1}$.

b Determined by GPC and calibrated by standard polystyrenes. 
Table IV. Figure 5 shows the ${ }^{1} \mathrm{H}$ NMR spectrum of the copolymer obtained in run 5 in Table IV as a typical example. Copolymer compositions were calculated from signal intensities of No. 5, 6, 9, and 12 in Figure 5. Figure 6 shows copolymer composition diagrams in aldol-coGTP of the silyl dienolate and enolate monomers. According to the extended Kelen-Tüdös method, ${ }^{13}$ the reactivity ratio in aldol-coGTP of $\operatorname{BdTBDMS}\left(\mathrm{M}_{1}\right)$ $\operatorname{VOTBDMS}\left(\mathrm{M}_{2}\right)$ was determined as $r_{1}=11.3$

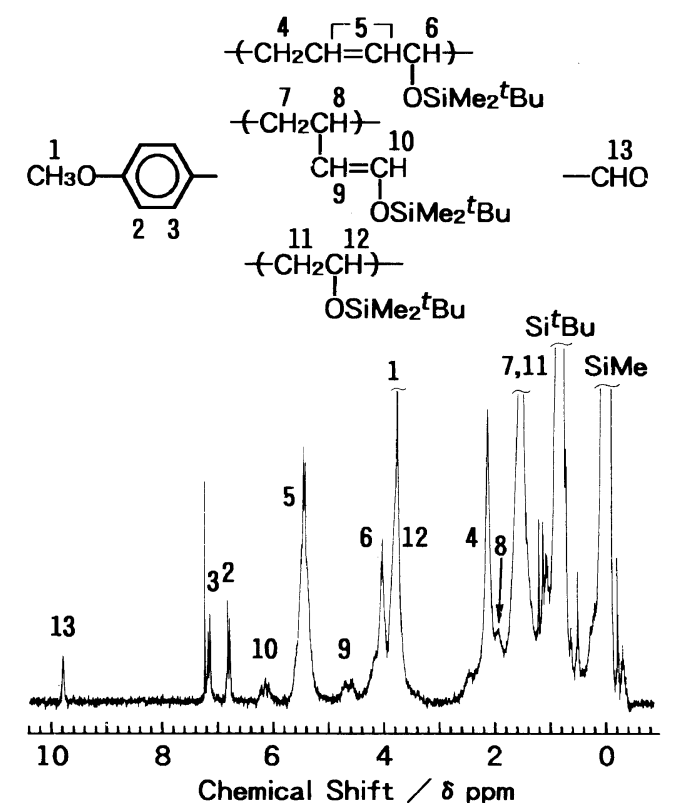

Figure 5. ${ }^{1} \mathrm{H}$ NMR spectrum of copolymer of BdTBDMS and VOTBDMS (run 5 in Table IV).

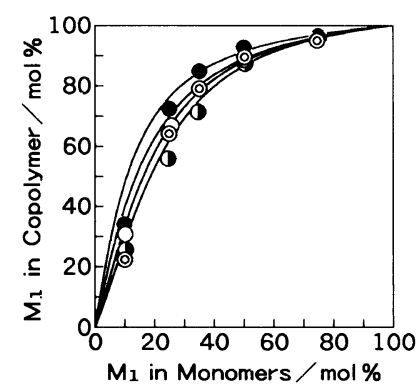

Figure 6. Copolymer composition diagrams in aldolcoGTP: O, BdTBDMS( $\left.\mathbf{M}_{1}\right)$-VOTBDMS $\left(M_{2}\right)$; $\operatorname{BdTMS}\left(\mathbf{M}_{1}\right)-\operatorname{VOTMS}\left(\mathbf{M}_{2}\right)$; ○, $\operatorname{BdTBDMS}\left(\mathbf{M}_{1}\right)$ $\operatorname{VOTMS}\left(\mathbf{M}_{2}\right) ;$ O, $\operatorname{BdTMS}\left(\mathbf{M}_{1}\right)-\operatorname{VOTBDMS}\left(\mathbf{M}_{2}\right)$. and $r_{2}=0.16$. Similarly, $\left(r_{1}, r_{2}\right)$ values for $\operatorname{BdTBDMS}\left(\mathrm{M}_{1}\right)-\operatorname{VOTMS}\left(\mathrm{M}_{2}\right), \operatorname{BdTMS}\left(\mathrm{M}_{1}\right)$ $\operatorname{VOTBDMS}\left(\mathrm{M}_{2}\right)$, and BdTMS( $\left.\mathrm{M}_{1}\right)$-VOTMS$\left(\mathrm{M}_{2}\right)$ pairs were calculated as $(8.88,0.33)$, $(8.73,0.22)$, and $(8.30,0.43)$, respectively. Taking account of the rather few data and experimental error, these values could be regarded as almost the same. The copolymerizability of the silyl dienolate monomer was obviously superior to that of the silyl enolate monomer. This seems that the length of conjugated system of the monomer determines its copolymerizability. Silyl dienolate monomers possess the longer conjugated $\pi$ system than the enolate monomers. When an incoming monomer is the silyl dienolate and its nucleophilic addition to the propagating formyl cation takes place, positive charge can be delocalized on the conjugated system. However, in the case of silyl enolate as the incoming monomer, such delocalization cannot occur. Consequently, the activation energy of the propagation of silyl dienolate monomers must be lower than that of enolate monomers. Differences in organosilyl groups (TBDMS and TMS) were not very important to determine copolymerizability.

\section{Effects of 3-Substituent of Silyl Dienolate Monomer}

Aldol-coGTP of the silyl dienolate monomer having methyl group at 3-carbon and unsubstituted dienolate monomer, namely MeBdTMS-BdTBDMS or MeBdTMSBdTMS, was carried out, and the results are summarized in Table V. Since homopolymerization of MeBdTMS was considerably slow, twice the molar amounts of $\mathrm{ZnBr}_{2}$ were used. However, MeBdTMS was more easily incorporated in the resulting copolymer than BdTBDMS or BdTMS. Figure 7 shows copolymer composition diagrams in aldolcoGTP of MeBdTMS( $\left.\mathbf{M}_{1}\right)$-BdTBDMS $\left(\mathbf{M}_{2}\right)$ and $\operatorname{MeBdTMS}\left(\mathbf{M}_{1}\right)-\operatorname{BdTMS}\left(\mathbf{M}_{2}\right)$. Evaluation of reactivity ratios by the extended Kelen-Tüdös method ${ }^{13}$ showed in $r_{1}=1.4$ and 
Table V. Aldol-coGTP of MeBdTMS with BdTBDMS or BdTMS in toluene at $0^{\circ} \mathrm{C}^{\mathrm{a}}$

\begin{tabular}{|c|c|c|c|c|c|c|}
\hline \multirow{2}{*}{ Run } & \multirow{2}{*}{$\begin{array}{l}\text { Monomer feed } \\
\mathrm{mol}_{\%} \text { of } \mathrm{M}_{1}\end{array}$} & \multirow{2}{*}{$\begin{array}{l}\text { Time } \\
\min \end{array}$} & \multirow{2}{*}{$\begin{array}{c}\text { Yield } \\
\%\end{array}$} & \multicolumn{3}{|c|}{ Copolymer } \\
\hline & & & & $\mathrm{mol} \%$ of $\mathrm{M}_{1}$ & $M_{n}^{\mathrm{b}} \times 10^{-3}$ & $M_{w} / M_{n}^{\mathrm{b}}$ \\
\hline \multicolumn{7}{|c|}{$\operatorname{MeBdTMS}\left(\mathrm{M}_{1}\right)-\operatorname{BdTBDMS}\left(\mathrm{M}_{2}\right)$} \\
\hline 1 & 75.1 & 10.0 & 10.4 & 79 & 0.8 & 1.67 \\
\hline 2 & 50.2 & 3.0 & 9.5 & 67 & 1.2 & 1.80 \\
\hline 3 & 35.6 & 1.5 & 13.0 & 52 & 2.6 & 1.50 \\
\hline 4 & 25.1 & 0.5 & 9.7 & 39 & 2.4 & 1.46 \\
\hline 5 & 10.7 & 1.0 & 5.4 & 17 & 1.7 & 1.62 \\
\hline \multicolumn{7}{|c|}{$\operatorname{MeBdTMS}\left(\mathrm{M}_{1}\right)-\operatorname{BdTMS}\left(\mathrm{M}_{2}\right)$} \\
\hline 6 & 75.4 & 3.0 & 7.4 & 85 & 1.1 & 1.69 \\
\hline 7 & 49.9 & 3.0 & 15.3 & 72 & 2.9 & 1.67 \\
\hline 8 & 35.7 & 1.0 & 14.3 & 58 & 2.7 & 1.65 \\
\hline 9 & 25.1 & 0.8 & 15.2 & 49 & 2.8 & 1.72 \\
\hline 10 & 9.5 & 0.8 & 11.5 & 19 & 1.7 & 1.81 \\
\hline
\end{tabular}

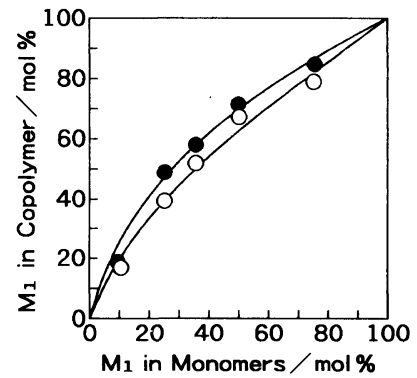

Figure 7. Copolymer composition diagrams in aldolcoGTP: $O, \operatorname{MeBdTMS}\left(\mathrm{M}_{1}\right)-\operatorname{BdTBDMS}\left(\mathrm{M}_{2}\right)$; $\operatorname{MeBdTMS}\left(\mathbf{M}_{1}\right)-\operatorname{BdTMS}\left(\mathbf{M}_{2}\right)$.

$r_{2}=0.42$ for the former pair, and $r_{1}=2.0$ and $r_{2}=0.29$ for the latter pair. The higher copolymerizability of MeBdTMS than unsubstituted silyl dienolate monomers, BdTBDMS and BdTMS, may be attributed to hyperconjugation effect of the methyl substituent.

The presence of a cross-propagated dyad in the copolymers has been predicted confidently using the initiators $1-3$. Here we note some other evidence confirming that the products are the copolymers in practice and not a mixture of each homopolymer. The product polymer obtained by aldol-coGTP of BdTBDMS and
MeBdTMS was treated with THF-acetic acid-water $(5: 3: 1)$ to cause desilylation of only TMS groups. If the product polymer should be a mixture of each homopolymer, the products after desilylation may be separated into soluble and insoluble portions in methanol. However, no insoluble homopolymer of BdTBDMS was obtained. Thus, the product polymer is a copolymer. Figure $8 \mathrm{a}$ shows the expanded ${ }^{1} \mathrm{H}$ NMR spectrum of the siloxymethine region $(4.0-4.6 \mathrm{ppm})$ of the polymer obtained in run 3 in Table $V$ (containing $52 \mathrm{~mol} \%$ MeBdTMS unit). The siloxymethine signal was split into four peaks. The chemical shift of the peak at the highest magnetic field ( 1 in Figure 8a) was in agreement with that of siloxymethine proton of BdTBDMS homopolymer, while the chemical shift of the peak at the lowest magnetic field (4 in Figure 8a) was in agreement with that of MeBdTMS homopolymer. The inner two peaks (2 and 3 ) did not appear in the spectrum of any homopolymer. The presence of the peaks absent in each homopolymer suggests that the product is a copolymer, not a mixture of homopolymers. The splitting of the siloxy- 


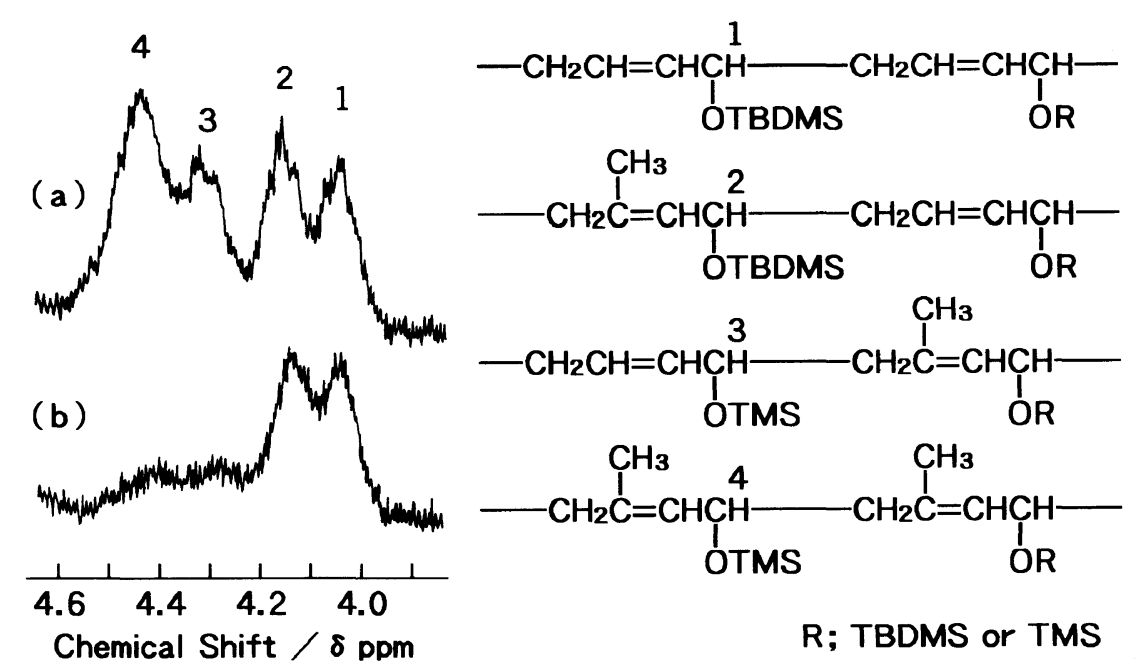

Figure 8. ${ }^{1} \mathrm{H}$ NMR spectra of siloxymethine region of (a) copolymer of MeBdTMS and BdTBDMS and (b) acetylated copolymer.

methine proton was due to the dyad sequences of MeBdTMS and BdTBDMS units. The polymer was treated with THF-acetic acidwater, and reacted with acetic anhydride in pyridine, converting its hydroxy group to acetoxy group. Figure $8 \mathrm{~b}$ shows the ${ }^{1} \mathrm{H}$ NMR spectrum of the siloxymethine region of the acetylated polymer. In comparison with the spectrum of the original polymer in Figure 8a, two peaks at higher field (1 and 2 in Figure 8a) did not change, and two other peaks at lower field ( 3 and 4 ) disappeared. Consequently, the two peaks at higher field in Figure 8 a are due to $t$-butyldimethylsiloxymethine protons, and the two other peaks at lower field are due to trimethylsiloxymethine protons. In aldol-GTP, the silyl group in a certain monomeric unit in the product polymer is transferred from the next monomeric unit. Thus, the four split peaks can be assigned to the siloxymethine protons in the four dyad sequences as shown in Figure 8. Such spectroscopic and chemical evidence can be noted also for other copolymers having TBDMS and TMS groups.

\section{Differences in Geometry of Silyl Dienolate Monomer}

Remarkable differences between $E$ - and
$Z$-isomers of silyl dienolates have been noted in homopolymerization via aldol-GTP process. ${ }^{9}$ Although copolymerization of both isomers is desired to estimate reactivity directly, this may result in vague data because of probable trace amounts of $Z$-isomer incorporated in the (co)polymer and structural resemblance of both units. There is no considerable difference between TMS and TBDMS derivatives of $E$-monomer, and thus $Z$-BdTBDMS instead of Z-BdTMS may be used. The TBDMS group will be detected clearly by ${ }^{1} \mathrm{H}$ NMR, even if a small amount of $Z$-BdTBDMS is incorporated in the polymers. Thus aldol-coGTP of $E$-BdTMS- $Z$ BdTBDMS and VOTBDMS-Z-BdTMS was carried out and the results are summarized in Table VI. In aldol-coGTP of a mixture of $E$-BdTMS and $Z$-BdTBDMS (runs $1-5$ ), the polymer could hardly be obtained. A sharp signal due to TBDMS group was found at $0.9 \mathrm{ppm}$ in the ${ }^{1} \mathrm{H}$ NMR spectrum of the polymer obtained in run 1 , suggesting that $Z$-BdTBDMS could slightly be polymerized under given conditions. However, it is doubtful whether $Z$-BdTBDMS reacted with a propagating end in the same manner as $E$-BdTMS.

Contrary to our expectation, aldol-coGTP 
Table VI. Aldol-coGTP of $E$-BdTMS-Z-BdTBDMS and VOTBDMS-Z-BdTMS in toluene at $0^{\circ} \mathrm{C}^{\mathrm{a}}$

\begin{tabular}{|c|c|c|c|c|c|c|}
\hline \multirow{2}{*}{ Run } & \multirow{2}{*}{$\begin{array}{l}\text { Monomer feed } \\
\text { mol\% of } M_{1}\end{array}$} & \multirow{2}{*}{$\begin{array}{c}\text { Time } \\
\mathrm{h}\end{array}$} & \multirow{2}{*}{$\frac{\text { Yield }}{\%}$} & \multicolumn{3}{|c|}{ Copolymer } \\
\hline & & & & $\mathrm{mol}^{\%}$ of $\mathrm{M}_{1}$ & $M_{n}^{\mathrm{b}} \times 10^{-3}$ & $M_{w} / M_{n}^{\mathrm{b}}$ \\
\hline \multicolumn{7}{|c|}{$E$-BdTMS(M $\left.\mathrm{M}_{1}\right)-Z$-BdTBDMS( $\left.\mathrm{M}_{2}\right)$} \\
\hline 1 & 74.7 & 0.1 & 6.5 & 96 & 1.6 & 1.77 \\
\hline 2 & 49.8 & 0.5 & trace & - & - & - \\
\hline 3 & 25.6 & 9.0 & none & - & - & - \\
\hline 4 & 16.5 & 4.5 & none & - & - & - \\
\hline 5 & 10.3 & 4.5 & none & - & - & - \\
\hline \multicolumn{7}{|c|}{$\operatorname{VOTBDMS}\left(\mathrm{M}_{1}\right)-Z-\operatorname{BdTMS}\left(\mathrm{M}_{2}\right)$} \\
\hline 6 & 89.7 & 0.25 & 8.6 & 93 & 2.0 & 1.97 \\
\hline 7 & 74.7 & 0.5 & 7.6 & 86 & 1.6 & 1.77 \\
\hline 8 & 49.8 & 1.0 & 9.4 & 69 & 1.8 & 1.82 \\
\hline 9 & 35.3 & 2.0 & 7.4 & 57 & 1.3 & 1.77 \\
\hline 10 & 25.3 & 11.0 & 5.0 & 53 & 0.8 & 1.61 \\
\hline
\end{tabular}

a Carried out with $p$-anisaldehyde as an initiator in the presence of $\mathrm{ZnBr}_{2}$ (1.6 moll $1^{-1}$ solution in diethyl ether): $\left(\left[\mathrm{M}_{1}\right]_{0}+\left[\mathrm{M}_{2}\right]_{0}\right), 1.0 \mathrm{moll}^{-1} ;[p \text {-anisaldehyde }]_{0}, 3.3 \mathrm{mmoll}^{-1} ;\left[\mathrm{ZnBr}_{2}\right]_{0}, 3.3 \mathrm{mmoll}^{-1}$.

b Determined by GPC and calibrated by standard polystyrenes.

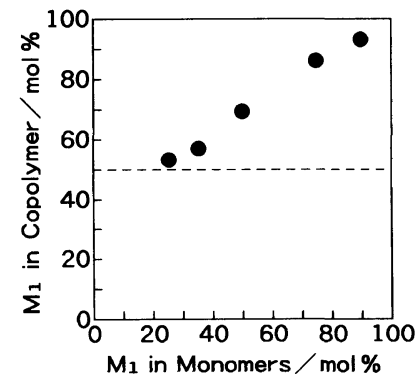

Figure 9. Copolymer composition diagram in aldolcoGTP of VOTBDMS $\left(M_{1}\right)-Z$-BdTMS $\left(M_{2}\right)$.

of VOTBDMS and $Z$-BdTMS (runs 6-10 in Table VI) gave copolymers. As the content of $Z$-BdTMS in monomer feed increased, the content of $Z$-BdTMS unit in the polymer gradually approached $c a .50 \mathrm{~mol} \%$, as depicted in Figure 9. However, the polymerization rate became slower and the molecular weight of the polymers tended to lower. This is often observed for copolymerization in which one of the comonomers could not give rise to homopolymerization. Consequently, Z-BdTMS could react with only the VOTBDMS end of the copolymer. The copolymer must have an almost alternating structure.
The structure of the copolymer from VOTBDMS and $Z$-BdTMS was essentially the. same as that of VOTBDMS and $E$-BdTMS. It seems proper that s-trans form is the predominant form in Z-BdTMS. Evidence for the presence of cross-propagation was obtained by the ${ }^{1} \mathrm{H}$ NMR spectra of the product polymers. Signals coinciding with the TBDMS group of $E$-BdTBDMS homopolymer were found in the spectra. Nevertheless, Z-BdTMS was used as a comonomer. This suggests that the TBDMS group is transferred from the incoming VOTBDMS to the Z-BdTMS end, as shown in Scheme 4.

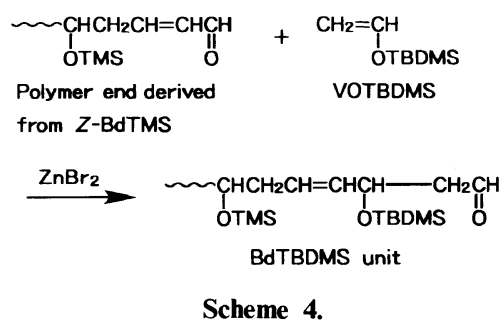

\section{Mechanism of Aldol-GTP}

Two possible propagation mechanisms for 


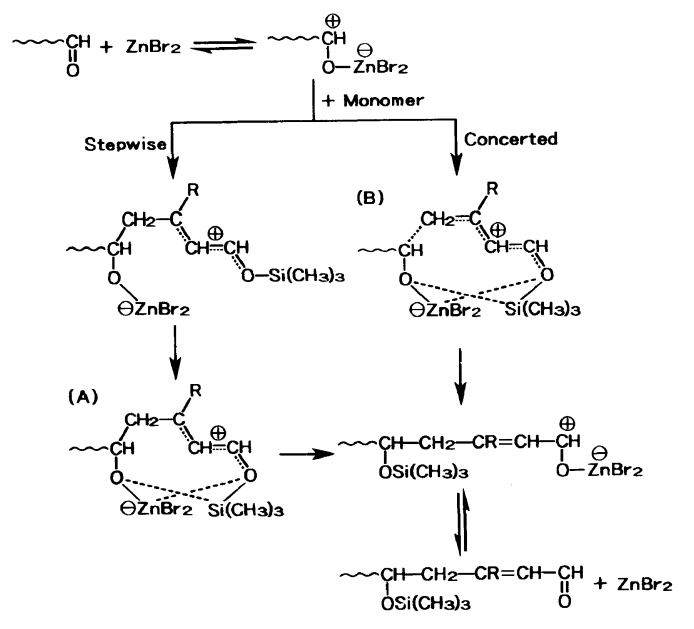

Scheme 5.

the aldol-GTP of silyl dienolates have been proposed on the basis of kinetic ${ }^{8}$ and stereochemical $^{9,10}$ investigations, as shown in Scheme 5. One is a "stepwise" mechanism, and the other is a "concerted" mechanism. The bicyclic transition state (A) or (B) is regarded as important from the standpoint of the stereochemistry of the resulting polymers.

The present copolymerization data indicate that transfer of organosilyl group from the incoming monomer onto formyl oxygen of the polymer end is not an important step determining the propagation rate of aldolGTP. This implies that (1) in the stepwise mechanism, the rate-determining step of propagation is the carbon-carbon bond formation between monomer and formyl carbocation in the propagating end, and that (2) in the concerted mechanism, almost the same activation energy for transition state (B) is required regardless of the different organosilyl groups. It seems that the stepwise mechanism is preferred to the concerted one. However, it is still ambiguous which mechanism is more applicable, since the organosilyl group was placed outside the cyclic structure in (B) as well as (A) and therefore it could not play an important role. The rate-determining step is, as a whole, a nucleophilic addition of the incoming monomer to formyl cation produced by coordination with $\mathrm{ZnBr}_{2}$.

The reciprocals of monomer reactivity ratios $\left(1 / r_{1}\right.$, BdTMS as $\left.\mathrm{M}_{1}\right)$ were the following order: $\operatorname{MeBdTMS}\left(1 / r_{1}=3.4\right)>\operatorname{BdTBDMS}(1.1) \approx$ $\operatorname{BdTMS}(1.0)>\operatorname{VOTMS}(0.12) \approx \operatorname{VOTBDMS}-$ $(0.11) \gg Z$-BdTMS and Z-BdTBDMS $(\approx 0)$. Figure 10 shows schematic potential energy changes along the reaction coordinate forpropagation in aldol-coGTP, mainly using a model in which BdTMS and VOTMS competitively added to the BdTMS unit as the polymer end, i.e., $\alpha, \beta$-unsaturated aldehyde. Activation of the BdTMS end by $\mathrm{ZnBr}_{2}$ (from a to c) must be smooth in comparison with that of a VOTMS end, i.e., saturated aldehyde (from $\mathbf{a}^{*}$ to $\mathbf{c}^{*}$ ) because of allylic resonance in its cationic form. Peaks $\mathbf{d}$ and $\mathbf{d}^{*}$ represent transition states of nucleophilic addition of each monomer to the activated polymer end, and troughs $\mathbf{e}$ and $\mathrm{e}^{*}$ represent propagation intermediates after forming new carbon-carbon bonds. The potential energy level of the intermediate $e$ must be lower than that of $\mathbf{e}^{*}$, because the positive charge in $\mathbf{e}$ can be delocalized on the allylic structure. In the case of propagation of MeBdTMS, the corresponding intermediate is further stabilized by hyperconjugation of methyl substituent. Stabilities of the transition states $\mathbf{d}$ and $\mathbf{d}^{*}$ parallel stabilities of the intermediates $\mathbf{e}$ and $\mathbf{e}^{*}$, respectively. Thus the activation energy for nucleophilic addition of BdTMS (from $\mathbf{c}$ to d) would be smaller than that for nucleophilic addition of VOTMS (from $\mathbf{c}$ to $\mathbf{d}^{*}$ ). Peaks $\mathbf{f}$ and f* represent transition states of the "group transfer" process. Their activation energies must be fairly small in comparison with those of the rate-determining step $\left(\mathbf{c} \rightarrow \mathbf{d}\right.$ and $\left.\mathbf{c} \rightarrow \mathbf{d}^{*}\right)$. The activation energies for the "group transfer" processes $\left(e \rightarrow f\right.$ and $\left.\mathbf{e}^{*} \rightarrow \mathbf{f}^{*}\right)$ scarcely depend on different organosilyl groups of the monomers because no significant effect of the organosilyl group on copolymerization was observed. Dotted curves in Figure 10 represent propagations of BdTBDMS and VOTBDMS. 
Stepwise Mechanism

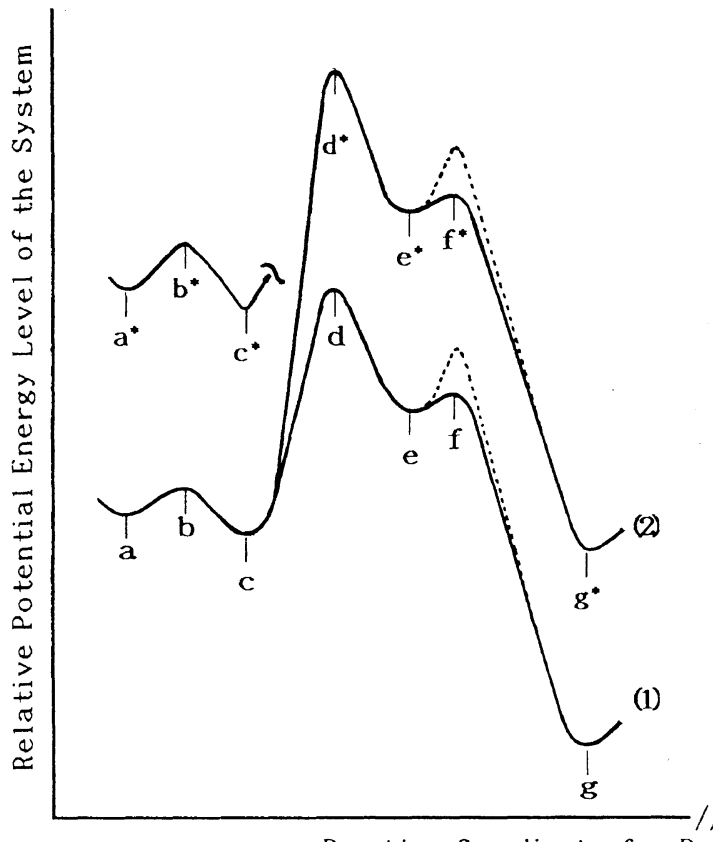

Reaction Coordinate for Propagation in aldol-coGTP

\section{Concerted Mechanism}

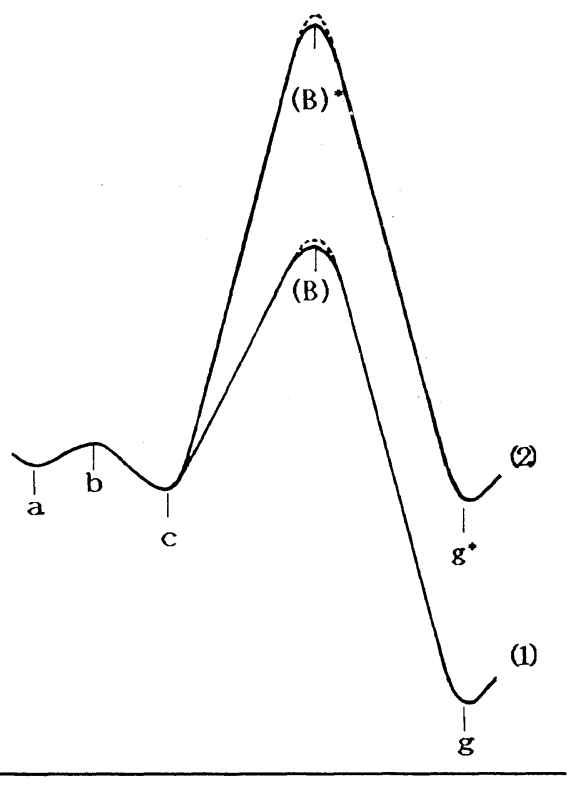

(1)

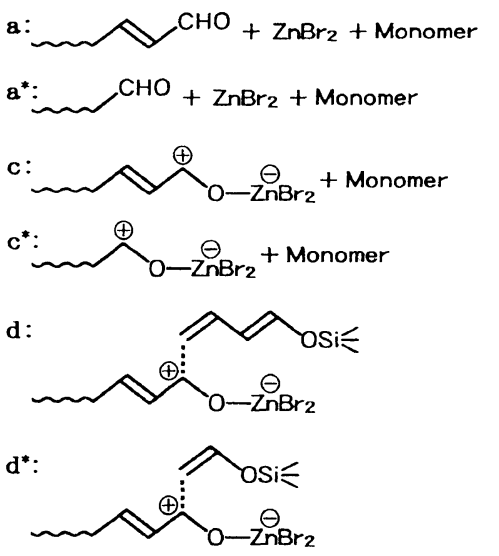<smiles>[R6]OC(C=CCCC)CC=CC=CO[Si](C)(C)C</smiles><smiles>CCCC=CC(CC=[O+][Si](C)(C)C)OC(=O)OCc1ccccc1</smiles>

f :

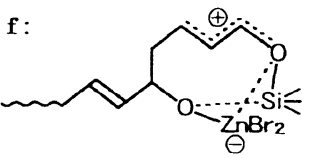

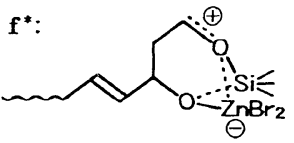<smiles></smiles>

$\mathbf{g}^{*}$ :<smiles>CCCC=CC(C[CH2+]O)O[SiH](C)Br</smiles>

B:

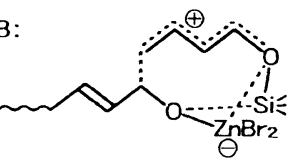

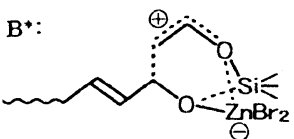

Figure 10. Relative potential energy changes for propagations of (1) BdTMS and (2) VOTMS from $\alpha, \beta$-unsaturated formyl group in a polymer end. Dotted curves are tentatively drawn for propagations of BdTBDMS and VOTBDMS.

The lowest polymerizability of $Z$-monomer is attributed to the difficulty in forming the transition state $\mathbf{f}$ of the "group transfer" process. Troughs $\mathbf{g}$ and $\mathbf{g}^{*}$ correspond to new propagating polymer ends having $\alpha, \beta$ unsaturated and saturated formyl groups, respectively. The former must be much more stabilized by allylic resonance. 
In the concerted mechanism, nucleophilic addition and transfer of organosilyl group proceed all at once through the transition state (B). Therefore, the polymerizability of each monomer may be explained by the stability of $\mathbf{g}$ and $\mathbf{g}^{*}$. It seems reasonable to assume that dienyl skeleton of BdTMS is stereochemically advantageous to form state (B). ${ }^{9}$ The potential energy level of state (B) must be lower than that of $(B)^{*}$, because the positive charge in $(B)$ can be delocalized on the conjugated system. In the cases of propagations of BdTBDMS and VOTBDMS (dotted curves), potential energy levels of the transition states are almost the same as the cases of BdTMS and VOTMS, respectively.

Acknowledgments. This study was partly supported by a Glant-in-Aid for Scientific Research (No. 05650896) from the Ministry of Education, Science, and Culture of Japan to one (T.H.) of authors.

\section{REFERENCES}

1. D. Y. Sogah and O. W. Webster, Macromolecules,
19, 1775 (1986); F. P. Boettcher, Makromol. Chem., Makromol. Symp., 13/14, 193 (1988).

2. W. Risse and R. H. Grubbs, Macromolecules, 22, 1558 (1989).

3. B. Charleux and C. Pichot, Polymer, 34, 195 (1993); Y. Kawakami, T. Aoki, and Y. Yamashita, Polym. Bull., 18, 473 (1987).

4. T. Hirabayashi, T. Ito, and K. Yokota, Polym. J., 20, 1041 (1988).

5. T. Hirabayashi, T. Kawasaki, and K. Yokota, Polym. J., 22, 287 (1990).

6. H. Sumi, T. Hirabayashi, Y. Inai, and K. Yokota, Polym. J., 24, 669 (1992).

7. Y. Mori, H. Sumi, T. Hirabayashi, Y. Inai, and K. Yokota, Macromolecules, 27, 1051 (1994).

8. H. Sumi, A. Suzuki, T. Hirabayashi, Y. Inai, and K. Yokota, Polym. J., 26, 705 (1994).

9. H. Sumi, K. Haraguchi, Y. Inai, T. Hirabayashi, and K. Yokota, Polym. J., 26, No. 11 (1994).

10. H. Sumi, K. Haraguchi, Y. Inai, T. Hirabayashi, and K. Yokota, Polym. J., submitted.

11. M. E. Jung and R. B. Blum, Tetrahedron Lett., 43, 3791 (1977).

12. G. Demailly, J. B. Ousset, and C. Mioskowski, Tetrahedron Lett., 25, 4647 (1984).

13. F. Tüdös, T. Kelen, T. F. Berezsnich, and B. Turcsányi, J. Macromol. Sci. Chem., A10, 1513 (1976); T. Kelen, F. Tüdös, and B. Turcsányi, $J$. Polym. Sci., Polym. Chem. Ed., 15, 3047 (1977). 